\title{
Multimedia Authorship Tool for the Teaching of Foreign Languages and Distance Learning in a Multiagent Environment
}

\author{
Adroaldo Guimarães Rossetti ${ }^{1}$, Almir dos Santos Albuquerque ${ }^{2}$, \\ Vasco Pinto da Silva Filho ${ }^{2}$ and Rogério Cid Bastos ${ }^{3}$ \\ ${ }^{1}$ Researcher at Embrapa Agroindústria Tropical, \\ ${ }^{2}$ Student Doctorate in Engineering and Knowledge Management-EGC, Federal University \\ of Santa Catarina-UFSC, \\ ${ }^{3}$ Professor of Graduate Engineering and Knowledge Management-EGC, Federal University \\ of Santa Catarina-UFSC \\ Brazil
}

\section{Introduction}

The agility of progress in the globalized world, in communications, in technology and in organizational activities demands more and more that people have formal knowledge of other languages. In this context, control of at least secondary level knowledge and other languages, such as the English language, predominant in practically all areas of knowledge and activities, is presented almost as survival need in people's lives. Although this reality is practically national conscience, official teaching, particularly in Brazil, doesn't seem to lead a way to suppress that need in a short term.

The Law of Basis and Guidelines of National Education (LDBEN) N 9394, of December 20th, 1996 (BRAZIL, 1996), in Article 24, deals with basic education, in elementary and secondary levels. Topic IV of this article mentions that:

[...] classes can be organized, with students of distinct grades, with equivalent levels of knowledge in the subject, for the teaching of foreign languages [...].

As far as is known, however, this still doesn't seem to be a reality, at least in official establishments, where education is offered by Brazilian state. It is understood that only what is settled on $\S 5^{\circ}$, of article 26 is followed, in which mentions that:

[...] in the diverse part of the curriculum, will be included, necessarily, as of fifth grade, the teaching of at least one modern foreign language, which will be chosen by the scholar community, within the institution's possibilities.

Despite not making explicit which "modern foreign language", English and French usually prevail in most regions of the country. This prevalence is a sharp expression of the recognition of the importance of the English language. It is convenient to register, however, according to Rossetti et al. (2009), that in regions with strong influence of immigrants (Germans, Italians, Japanese, etc), such as the South and the Southeast, this prevalence is less accentuated. 
Even with the inclusion, "necessarily as of the fifth grade", independent of the language, this condition offers only elementary notions especially for two reasons. First, because the teaching of this language doesn't continue throughout the entire period, as the expression "as of" suggests. Second, the scantiness of the class schedule doesn't allow bigger advancements and stops there, not offering good learning conditions for foreign languages. Except for those who enroll in university, in a Letters course, where they can really specialize in any given language, there are few alternatives to deepen knowledge in this area. The only option left to acquire suitable knowledge are private foreign languages institutes or schools, which almost always have high costs and inflexible hours, which, in general, keep a considerable part of the population from inserting themselves in this process.

Some linguistic conceptions found in educational softwares hold two stages: one consists in the structural analysis of a sequel derived from the base; the other, of a structural change in that sequel. This premise supports the linguistic conception of this work, which originates from an analysis of the situation of foreign language teaching in Brazil, to then discuss the possible transformations caused by the suggested model. The methodological conception, on its turn, is centered in the study and analysis of the problems of teaching a foreign language in Brazil, identifying the causing factors which will be considered by the intervention of the proposed tool.

Both in secondary school, distance learning and undergraduate teaching and in traditional foreign language teaching, usually classes are ministered in days and times determined by the school, according to a predetermined calendar, almost always inflexible. This system, which does have its upsides, can hurt students that, for any given reason, are prevented from watching one or more classes successively. The same problem can be transferred to those who, for whatever circumstance, are eventually compelled to a temporary interruption of frequency in a determined module of the course, independent of the stage of said module. The occurrence of any of these cases may cost the student to lose track of taught subject, making it harder to progress with good improvement, once that, in cases of this nature, missed classes can hardly be recovered parallel to the normal course due to a number of factors. When a lot of classes are missed, the time needed solely make it not viable; when the missed classes are few and the time is available, the elevated costs usually imposed can be unviable to many students. On the other hand, students who learn any subject or language easily, with conditions to progress more rapidly are, sometimes, also penalized, once this structure usually doesn't support the structuring of classes that take this characteristic under consideration. And when that is possible, classes in general have few students, increasing costs, making it an obstacle for many. Under these circumstances, waiting for the start of a new class in the same level or module has been an alternative for those who wish to do it well, although that implies increasing the learning time of a given discipline or domain of the language of study.

Workers who wish to deepen their knowledge face not so different situations, sometimes, even for professional needs. In that sense, Pettenati et al. (2000) mentions that because of distance or difficulties to conciliate organizational appointments, a lot of people face difficulties to progress in the acquisition of knowledge and competence, for in the majority of times, these aspects depend on a teacher not always available in organizations.

Therefore, the lack of flexibility to start or restart a course, particularly a foreign language one in any period, time or place, is a problem to be dealt with, due to the importance of a 
teacher in this type of teaching and learning. In these courses, more than in any other, aspects such as pronunciation, hearing perception, repetition, reading and writing, for instance, have great importance and are object of orientation by the teacher through teaching material and exercises. Furthermore, these characteristics practically constitute the four abilities of language: understanding oral language, speaking, reading and writing, in which bases, according to Widdowson (1991), the courses of foreign languages are established. These abilities refer to the type of activities students must do when coursing an idiom, which a lot of teachers agree with. Therefore, those should be the bases for generating teaching material for these courses.

A flexible structure is needed, one that allows the interested person to initiate the course in any period, time and place, according to their possibilities, conveniences and to the level of knowledge they already have of the discipline or language which they wish to take. Or retake, from where eventually happened the interruption. Plus, it should allow those who learn more easily the possibility of completing their studies more rapidly, according to their abilities, necessities, availability or conveniences. It is essential to have, in this structure, teaching material, texts, reading and writing orientation; sounds and images that reflect clarity of pronunciation and develop hearing perception ability; exercises directed to improve pronunciation, the right spelling of words and the fluency, in case of idioms, besides exercises, referring to other available disciplines. It is also important to have a good dose of incentive and motivation to accelerate the learning process in the student.

Currently, however, according to Pettenati et al. (2000), these barriers are fully transposable with the help of Information and Communication Technology - ICT. The use of technology in this process is essential, for, according to Ramos (1996), the incorporation of technology to the learning process offers, concretely, the opportunity to implement a new model or teaching pattern. Furthermore, technology has the potential to produce new and rich learning situations. According to Coutaz (1990), the one who conceives an interactive system should offer a description, as accurate as possible, of the problems and cognitive processes of its user, in a way that it not only gives support, but also motivates, more and more, the learning process.

As stated by Kaskalis, Tzidamis \& Margaritis (2007), with the explosion of multimedia computation, educators have been trying to achieve a total human-computer interaction, favoring the progress of teaching and learning. Consequently, a great number of multimedia tools have been created, always following the tendency of a simpler and easier development of these tools. Many actions have been taken to facilitate this intention: since the use of the multiple computer resources to the introduction of series of variables to base an appropriate evaluation. So far, according to these authors, there is no news of a tool that has completely fulfilled such task.

For Bailey \& Konstan (2000), the lack of an authoring tool that favors the satisfactory interaction of the teaching and learning process happens because, although these tools are usually developed by great professionals in the computer area, it not always has the necessary cooperation of specialists in the subject to which the tool is destined. Besides, they are rarely validated with the participation of final user.

To Moran (2003), with the evolution of digital technology, online education has emerged as an excellent alternative for the advance of knowledge. To this author, online education involves a series of teaching and learning actions developed through telematic means, such as the Internet and the use of all its information and communication devices, useful to the improvement of inter-relational processes. 


\section{Technical revision}

Technological advancements have favored the implementation of support tools to the regular teaching of foreign languages process in an attempt to improve the methods of teaching and learning, such as the ones by Courtillon \& Raillard (1983) in the French Alliance, for instance. The execution of this practice consists in using the computer as a help instrument to teach the French language, using multimedia resources to listen, speak and write.

A number of initiatives have been taken with the use of technology, searching to make knowledge accessible to a greater deal of people. With that in mind, Pettenati et al. (2000) proposed a tool for distance learning, intending to make instruction available, without hurting the work, making it more accessible and efficient to whomever is interested, particularly employee and company. The proposed tool describes a webbased, author of a tutor learning system, conceived to suppress the difficulties of distance or organizational appointments. The environment is composed by several interconnected systems, including:

a. description of the course, with guidelines and agenda;

b. work plan and themes for revision of studied subjects; and

c. a structure that facilitates periodical self-evaluation.

It's a tool that, according to the authors, successfully complies with the goals it commits to. Under the technological education in the teaching area view, Knowledge Engineering, through Artificial Intelligence techniques, may be the way to offer more options to who wishes to widen their knowledge, due to the resources it has. There are many available approaches to work knowledge, involving the acquisition, the storage and the use of knowledge, for example. In that way, AI can be classified under various categories. As for problem solving method: in Symbolic AI (SAI), Conexionist AI (CAI), Evolutionary AI (EAI) and Hybrid AI (HAI). As for location: in Monolithic AI (MAI) and Distributed AI (DAI). SAI uses logic as a basic tool to deal with knowledge, with its rules of inference inspired in syllogisms. CAI using Artificial Neural Networks applies to "not well defined" problems, but that are made known through examples. Among the fields of application of the Conexionist techniques, including most importantly artificial neural networks, are: knowledge of patterns; control of industrial processes; robotics and as option to the reasoning techniques based in cases, for the resolution of problems. In EAI, the mechanisms used are the same ones found in biological evolution. It is an example of "well defined" problem, of survival of a species in a variable environment. It can be looked at as an optimization process, although having variable restrictions, and, sometimes unknown. HAI gathers advantages of more than one method of approach to resolution of problems. MAI involves simple systems with no modularity, such as the specialist systems, for instance. The operation of DAI depends on a certain group of parts (or modules) to resolve a determined problem in a cooperative form. Its modularity to find solutions to the problems is directly connected to the concept of agents.

It was with AI that the first systems for teaching through computers came about, with Computer Based Training - CBT, mentioned by McArthur, Lewis \& Bishay (2002), and Computer Assisted Instruction - CAI, referred by Beck, Stern \& Haugsjaa (1996). According to these authors, the system mentioned by the first ones usually generated groups of problems projected to increase the student's performance in domains based in abilities, such as arithmetic and vocabulary regaining. Furthermore, the decisions on how the student should navigate through the material were based on decision trees and the questions and 
answer sequence were directed by the hits and errors of the student, their individual abilities not being taken under consideration. To Urban-Lurain (1998), the recommended proposals in theses systems limited themselves to present a problem to the student: register the answer and evaluate performance, but the instructions were not individualized to their needs.

Virvou \& Moundridou (2009) used an Intelligent Tutoring System to develop an authorship tool for Web, destined to teachers and students in the domain of algebraic equations. When accessing the tool there is a "description" of a specific domain, given by a human teacher. The tool offers help to human teachers in exercise construction and, while the students resolve their exercises, "monitors" provide the suitable answers. It gathers intelligence in its component which executes diagnosis to the student's errors. It also controls the teaching material in a flexible and individualized way and executes intelligent analysis of the student's answers, providing interactive support to problem solving. Furthermore, the system adapts and takes note of the kind of connection the students make between their answers and the received support. The advantages of this system, according to Virvou \& Moundridou (2000), is that human collaborating tutors can be in the same physical space or distant and the students can be in a classroom, in a specific location, or in a virtual class, which can be spread through many physical locations, promoting distance learning. Trying to answer the question: is it possible to achieve efficient learning environments from a generic tool, applicable to all knowledge contexts, throughout the entire period of learning? Ainsworth (2007) developed an authorship environment called REDEEM, which proposes to achieve such goal, adapting existing interactive learning environments of multimedia authorship software (or courseware). REDEEM was developed on the Click2Learn ToolBook instructor and it is executed on Windows platform. The software consists of two main parts (the authorship tool REDEEM and a shell), where the "authors" and the students can interact through. The existing courses on ToolBook are about, among others, genetic topics; information and communication systems; PCs and network management; html courses; statistics and photography basics, for example.

The first big task to be executed is describing the domain material, which the system will use to make decisions on how to present the material to students. The second biggest aspect of authorship domain is adding interactivity. The "authors" create questions (multiple choice, fill in the blank, true-false or combined questions) and provide the answers that explain to the student why an answer is right. Five different suggestions can be created for each question, which according to Ainsworth (2007) increases specificity. The "author" also describes a number of question characteristics which the shell uses to implement a new specific teaching strategy (difficulty, pre or post-test, for example). Reflection points can also be added (as means to make the student alert to make note) or about a non computer related task (which drives the student's attention to another activity). Ainsworth (2007) followed REDEEM for ten years, comparing it to other coursewares and describes it as one of the most usable and easiest to learn. He recognizes, however, that due to its generality, some of the benefits that come from the rich specific knowledge domain had to be sacrificed.

To Crispim, Abdalla Júnior \& Molinaro (2002), a teaching cycle must meet the following requisites:

a. present information related to the teaching goal;

b. direct the students actions towards those goals;

c. value and evaluate the students actions;

d. provide feedback; 
e. provide orientation strategies to the student;

f. conduct and motivate the entire teaching process.

With that in mind, they claim that most classical distance learning environments present limitations in the implementation of interaction between student and teaching environment. These authors developed an environment using artificial intelligence techniques, specifically Bayesians networks (which are based on the strength of their causal representation of human reasoning and the ability to represent and react to configuration changes); neural networks (that try to approximate the computer processing model to the one of the human brain, for possessing a similar interconnection level to the one of the human brain and, in a conventional modern computer, the information is transferred in specific times within a synchronized relationship); workflow (which makes easier the organization of knowledge that is to be transferred to the student through the development of a group of paths, focused in different levels of explanation and respective exercises for subject learning tests); and software agent or intelligent agents (due to its characteristics: ability to explore a significant sum of knowledge domain; tolerance to unexpected errors or resulting of wrong entries; ability in the use of symbols and abstractions; adaptation capacity and goal oriented behavior; ability to learn from the environment; real time operation capacity; and ability of communication in natural language). To Crispim, Abdalla Júnior \& Molinaro (2002), the presented architecture corresponds to the inclusion of reasoning mechanisms in the learning environment model which will be responsible for the optimization of the construction process, knowledge transmission and intelligent learning.

An important step in that direction was taken by Barr, Cohen \& Feigenbaum (1990) with the development of the Intelligent Tutorial Systems - ITS, which main goal, according to Clancey \& Soloway (1990), was to reproduce the intelligent behavior (competent) of a human tutor, and can adapt its teaching methods to the students learning rhythm. In this context, according to Lévy (2000), the mail and the electronic conferences serve as intelligent tutors and may be placed at the cooperative learning device's service. The hypermedia supports (CD-ROM, online interactive multimedia database) allow fast and attractive intuitive access to great groups of information.

In this context, the multiagent systems have particular importance, for, according to Russel \& Norvig (1995), an Agent is a system capable of perceiving through sensors the information of the environment in which it is inserted, acting and reacting through actuators. Ferber \& Gasser (1991) reinforce this idea stating that an agent is a real or abstract entity, capable of acting on itself and on the environment, and has a representation of this environment, even if only partial. In a multiagent universe, it can communicate with other agents, which behavior derives from "its observations", from "its knowledge" and from the interaction with other agents. Bittencourt (2001) defends the idea that an "intelligent community" is the base of multiagent systems. This idea defines the system's intelligence as being the product of the "community's" social behavior which is made up of autonomous agents with cooperation capacity among themselves, with a common goal, which agents are inserted in the same environment. Gasser (1992) completes this reasoning claiming that an agent can be considered an entity capable of performing formal calculations and producing a certain number of actions, from knowledge and internal mechanism that are typical to them.

The multiagent system forms a sub-area of distributed AI and focus in the study of autonomous multiagents in a multiagent universe. To multiagent systems, the term autonomous means that the agents exist, independent of the existence of other agents. Usually, each agent has a group of behavioral capacities that define its competence, a group 
of goals and the necessary autonomy to use their behavioral capacities to reach their goals. To Álvares \& Sichman (1997), an agent is a computational entity with autonomous behavior that allows it to make its own actions. The main idea in a multiagent system is that a global intelligent behavior can be reached from the individual behavior of the agents. In these systems, it is not necessary for each agent to be individually intelligent in order to reach a global intelligent behavior. The intelligence metaphor used by multiagent systems is the "multiagent community", that is, the social behavior, which is the base for the systems intelligence. The metaphor used by classic AI is basically of psychological origin, while the one used by DAI can be of sociological or ethological. A sociological/ethological approach is interesting when the goal is to resolve complex problems, that require knowledge from various domains and that can involve physically distributed data.

The multiagent systems are usually characterized didactically in two classes: reactive and cognitive. Reactive multiagent systems work with a great number of simple agents in the development of systems for the resolution of a determined problem. They are based in models of biological or ethological organization. Its functional model is formed by the binomial stimulus-response (action-reaction). Cognitive multiagent systems work with few agents that perform much more complex tasks and are based in human social organizations such as groups, hierarchy and market, which characteristics are the base of this work.

This century has been branded by transition and by deep transformations, with extensive impacts in the educational process and pedagogical theories, so Azevedo (2000), Silva (2006) e Maia \& Mattar (2008) say. The creation and dissemination of new technologies, with the multiplication of connected computers networks, advancement of interactive medias and other forms of content transmission, besides books, have taken the world to new experiences and interaction forms, specially in the teaching-learning field and professional formation. A new space of communication, organization and information socialization, knowledge and education is being inhabited. In this context, a new modality of teaching stands out Distance Education, or Online Education, also called virtual formation environments. These resources allow people in different physical spaces to share, construct and trade information and knowledge, interactively, using various instruments or technological tools. This new modality of education allows flexibility and interactivity in the learning process, characteristics peculiar to the internet, instrument of construction of a communication culture, which methods demand new conducts.

These modern medias, in the case of Distance Education, allow both teachers and students, living anywhere in the world, to teach and learn, independent of where they live. There is flexibility to choose the best times and days for study, besides the student's possibility to even choose the rhythm that better adapts to their work, family or other situations. This form of education favors students that live in places distant from any educational institution, those who had to abandon studies by adversity or never even did study, to improve their knowledge. In a way, classroom instruction would not give them this opportunity, since it would require hundreds of schools and thousands of teachers, and additionally, a great volume of investment in infrastructure to achieve this task. Even so, the Brazilian legislation on Distance Education still imposes monitoring attendance that occurs when the teaching has the availability to go to communities where it is possible to gather a certain number of participant students.

This obstacle will be removed by a multimedia authoring tool, in multiagent systems that do not require human teachers, like the proposal of this work. The proposal of use of architectures in multiagent systems in Distance Education brings great advantages relating 
to traditional educational structures for presenting more flexibility in the treatment of elements that compose the system. The fact that Agents are used to model its components allows the grouping of the traditional structure or the expansion of each Module by the composing Agents.

Many applications have been developed, employing multiagent systems in the teaching and learning process, among which can be highlighted, for instance, the Multiagent System of Teaching and Learning on the Internet - SEMEAI. According to Geymer et al. (2003), this system's goal is to promote distance learning, using agent technology to adapt itself to each student's characteristics. That occurs by applying different forms of teaching that adapt to the psycho pedagogical aspect of the student, allowing effective retention in memory due to the diversity of forms and learning opportunities and its adaptation to the student. In this environment, the author directs the solution, highlighting three fundamental activities in a tutoring system:

a. adaptability to the student's profile, with the goal of providing more quality in the selection of available material;

b. automatic selection of adequate teaching strategies, with bases in good results attained by evaluations throughout the process. The environment can lead to the adoption of more suitable strategies to conduct the student's learning in a determined subject;

c. personalization of the teaching curriculum, through an specific agent, responsible for such activity. This personified character of the curriculum is defined as the selection of material according to established tactics in each teaching method that make up the selected strategy.

Fialho \& Alves (2001), using Virtual Reality techniques associated to the Theory of Cognitive Agents, developed a teaching tool with the goal of helping child, teenager and adult to learn, interact and dive into the process of knowledge sharing. These authors encourage the development of softwares for Child Education, for example, with the intention of improving teaching quality. That allows, according to them, the software to be the support to knowledge construction on children, teenagers and adults, and not merely a synonymous of "automation" of education. This means the development of softwares must recover Brazilian values, in this case, aiming for the approximation of reality.

Santos \& Osório (2003), trying to incentive the learning segment, presented an intelligent virtual three-dimensional environment adaptable to Distance Education. In this environment, used to make content available, the characteristic of adaptation is related to the possibility to reorganize them through process of insertion, removal or updating of information and personalization of the presentation of said content, according to the user's interests and preferences. For that, a content profile and a user profile are used in the adaptation process. Furthermore, the environment is inhabited by intelligent entities that act as the user's assistants during navigation and localization of relevant information, as well as helping with the organization of available content.

However, establishing these profiles is a complex task, which elements in general can't always be particularized, so they need to be considered under a group. For Morin (2004), complexity means a common texture that is presented as inseparably associated. This way, individual and environment, subject and object, order and chaos, professor and student, actions and life's "wefts" and other fabrics that conduct events need to be looked at from a general context. For this author, complex is what is weaved and must be considered as such. The separation in parts may cause the lost of context. This highlights the fact that knowledge is built by exchanges that nurture the relationship between subject and object, by dialogs, 
interactions, transformations and mutual enrichments, where nothing is linear or predetermined, but instead relational, undetermined, spontaneous, creative and new. Under that view, the technology that houses a teaching and learning system must hold these characteristics that imitate human behavior, gifted with these faculties.

According to Araújo (2007), the current teaching method does not support new tendencies on human subjectivity. In the author's opinion, there already is enough bases to a legitimate teaching transformation, knowing that one does not learn linearly, but instead moving the several dimensions of the human being. This moving will facilitate the reconfiguration of knowledge by being incorporated by students and will help find and attribute self sense to information native both from teachers and texts as well as from established dialogues in the teaching environment. It is from this process that emerges knowledge that allows the student to survive and transcend from a dialectical relationship between knowledge and action that happens through the joining of other human dimensions, including the sensorial, intuitive, emotional and rational which are known to be complementary.

In online environments based on the perspective of interactivity, the courses contents are built in a partnership process, where other authors create and socialize their knowledge in many ways: through softwares, interfaces, hypertexts and media. Araújo (2007) proposes the learning environment to be more interactive, with more student autonomy, with practices that contemplate different learning styles and others that stimulate the individual and collective knowledge building.

If, on the one hand, it has been difficult to produce an efficient authoring tool for multimedia or distance education, on the other hand, in the opinion of many researchers, including Kaskalis, Tzidamis \& Margaritis (2007), finding a way or tool to evaluate the efficiency of the teaching process and learning of the proposed tools is still a question with no answer.

Oliver (2000) introduced a tool to evaluate the learning level obtained by experts and by groups, through shared procedure. The evaluation, according to this author, is a complex process and can be characterized as a resource through which people make judgments on value concepts. In the learning technology context, however, it becomes too simple, in his opinion. The tool proposed by Oliver (2000) offers an instrument to analyze this complexity, through the comparison of two cases (experts and by groups) afore mentioned, which concluded that there is a higher learning level on shared learning process. This model in the tool aims to give appropriate support to the management of an organization, in this case; promote professional training; and program time in distance learning processes, without hurting activities.

Kaskalis, Tzidamis \& Margaritis (2007), aiming to find a tool that could serve a purely educational goal, evaluated 44 packages of authoring tools separately. They collected a reasonable amount of data which was treated as base in a five point scale, on which results the tools were evaluated. They reported the lack of data related to education, aiming to specify if it is possible for an authoring tool to be used by educators (with no particular ability) to facilitate a course in any field or subject. They could not find a software to clearly evaluate the educational part and finally concluded that, from the educational point of view, none of these tools had something special to offer to a learning environment.

To Collazos et al. (2007), many researches on collaborative work focus on the group the quality of the result as criteria for collaborative learning success. There are few researches on the collaborative process itself. Comprehending this process would not only help make it better, it would also help improve collaboration results. To these authors, understanding 
and evaluating collaborative learning processes requires defined analysis of group interaction in goals and learning context. Taking relations between tasks, products and collaboration under consideration, Collazos et al. (2007) presented a group of measures projected to evaluate the collaborative learning process. These procedures emphasize: direction of the base system; measures based on data produced by the collaborative learning system during the collaboration process; and suggest that these measures can be widened, considering perceptions of participants in the process.

The model proposed by the authors is based on the size of the collaborative learning process. For that, they produced quality indicators for the student's work during the cooperative learning phases, from a model of high collaborative learning level.

In the context of these advances, multiagent systems, which components, according to Oliveira (1998), should reason about the actions and about the coordination process among itself, constitute more flexible architectures, in a system organization that is subjected to change, trying to adapt itself to environment and/or problem to be resolved variation. Under this view, the goal of this chapter is to present the proposal of an authoring tool, in a multiagent environment, as instrument for teaching and learning a second language and distance education, multimedia, of any discipline. A tool continually available on the Internet, so that whoever is interested can use it at any time and place, according to their potentialities, conveniences and possibilities, with no harm to other activities they may eventually have.

\section{Material and methods}

The tool to be implemented will be based on a multiagent system, according to the vision of Heilmann et al. (1995), which agents, with "cooperative spirit", working together, will execute mutually benefic tasks, independent of its complexities. These tasks are destined to serve students and teachers of foreign languages and distance education, of any discipline. A system of this nature is intended to act as representative of others, with the goal of performing actions that benefit the represented part.

The agents, as entities of software that form a group of operation in favor of the user of another program with some level of independence and autonomy, do that, according to O'Connor et al. (1996), employing some knowledge or representation of the users goals and desires. For these characteristics, they are, therefore, essential to a tool that incorporates this function of serving, of benefiting the user. Another aspect that justifies the option for a multiagent system to base the proposed tool are its priorities of intelligence (capacity to dynamically realize the environment, perform actions that affect the environment conditions, understanding perceptions, problem solving, reach conclusions and act); perception (ability to realize and execute a task with more efficiency than on previous executions); communicability (capacity to communicate with the user, with other software agents or other processes); cooperativity (capacity to work together in order to reach a general goal through mutual assistance); mobility (capacity to move by itself through the electronic net or moving to one location to another, preserving its internal state); veracity (high level of trust that the agent represents exactly the user); autonomy ( capacity to operate by itself and execute actions with no user intervention); adaptability (capacity to process different task levels, accordingly to its competence); and many others, which advantages are widely discussed by many authors such as Gilbert \& Manny (1996). Such proprieties allow implementation of flexible structures, which organization easily adapts to 
environment or problem to be solved variation; this is the reason to its application in so many areas of knowledge and activity.

By allowing the representation of some reasoning abilities and specialist knowledge in the search for the solution of big problems in this area, these characteristics favor application to school activity and contribute with new teaching and learning methods. They also give the user the possibility to build new experiences and elaborate or create new mental models, as advised by Piaget (1983). In the specific case of teaching and learning foreign language binominal, the anthropomorphism of the agents has particular importance in representing human characteristics such as sounds, tone of voice, and others, so useful to the adequate expression of words, for instance.

The most relevant in the context of distance education of any discipline or foreign language is that multiagents systems constitute, one could say, a shared environment and, as such, are reflected on the growth and quality of knowledge, which growth happens as it is shared, as opposed to the capital of the industrial era, for example, that tended to grow as it was retained by its owner. So, there is the perspective that this character is maintained in the foreign language and other disciplines learning, with the use of this tool.

\section{Proposal}

The multimedia authoring tool for distance education, of any discipline or foreign language, based on multiagent systems, will give the student, independent of the knowledge level of the language discipline, more flexibility on the learning system, allowing total control over the process. The tool allows the development team of multimedia educational material to easily insert texts and objects such as figures, sounds and video, to create stories with dialogues, based on the didactic material used for the teaching of a foreign language or other discipline.

A multiagent architecture tries to assimilate the cooperation between people on human society to perform tasks within the tool and is transmitted by communication and message exchange between agents, aiming to execute determined activities. Based on the structure proposed in the tool, the teaching of foreign language will have its applicability contemplated in this methodology both for students and for the general work market. In the proposal presented here, based on a multiagent architecture, a specific function is attributed to each agent. To the performance of tasks associated to the role they have, the agents will implement specific cognitive abilities, with full communication and interaction between them, providing total functionality to the system. Unlike a centralized solution based solely in one base of knowledge, a structure distributed for knowledge is proposed here, as suggested by Rossetti et al. (2006). Thus, each agent will have its own base of knowledge, with the required representations for better treatment of the information it will use in the performance of its tasks and on the sharing and cooperation with other system agents, as seen on the conceptual framework of the diagram in Figure 1:

In this diagram, the rectangles represent the agents; in the circles are the Knowledge's Base $\mathrm{KB}$ of each agent's domain; the arrows represent the relations (communication) between agents; the "stick dolls" are real actors, among which, teacher and students are the main ones. The tool will be available and accessed through the Internet, in the Web, with no direct human interaction between teacher and student. The interaction between them will happen indirectly, through the agents Author and Learner, which represent them in the teaching environment, and serve as mediators in the process of exposition and learning of the 
content. In this context, the author agent, which represents the teacher on the system, will have the knowledge over the domain of application, which will allow the elaboration of content to the ministered lessons, using multimedia resources. These lessons, elaborated with the support of base-texts, will contain information about the knowledge domain over the foreign language to be ministered in various formats such as text, sound and image. Learning situation will be created toward hearing perception (pronunciation) and for the correct spelling of words (writing), in the foreign language case. It will be, therefore, based on the listening of texts with visual tracking of scenes for contextualization. In this process, the student must write, in an indicated field, the text of language of study, relative to what was heard and the system will verify the level of success obtained (total, partial or unsuccessful). The system immediately interacts giving feedback until total success is reached.

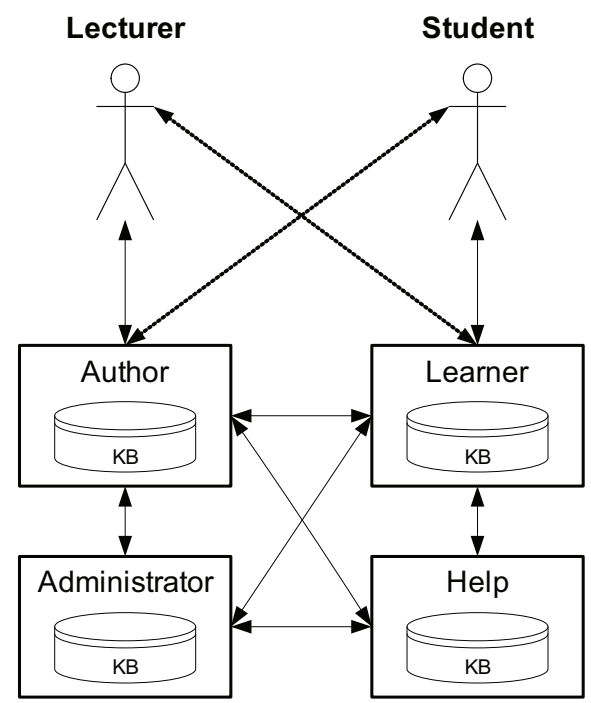

Fig. 1. Conceptual framework of multiagent environment for the teaching of foreign language or other disciplines

As an illustration of this interactive environment, consider, for example, that a dialogue in a foreign language has been created and recorded by the tool, which images are displayed to the student, offering conditions to contextualize the dialogue. The written text will not be presented. The student must listen to the dialogue and reach the conclusion that what was heard was understood, write what was understood in the referred field. The system will then verify if the student:

a. understood and was able to correctly reproduce the text, considering the exercise finished;

b. understood, but made small spelling errors when writing the text. In this case, the correct spelling is presented so that the student acknowledges it, considering the exercise finished;

c. did not understand. In these circumstances, the system offers the student two options: (i) suggest that he access "clues" in the system; (ii) follow a video displaying the 
phrases being pronounced slowly to facilitate comprehension. Then, the exercise is repeated so that the student consolidates the understanding, after which it is considered finished.

Furthermore, the tool will allow the development of additional didactic material for the classes, allowing students to exercise and develop, on their own rhythm, pronunciation, hearing perception and orthographic abilities. Exercises relating to those classes will also be created from image association, recorded dialogues and its corresponding texts. To each exercise will be associated a group of "clues", that can be chosen in new texts, sounds, images or videos. The clues are intended to be associated with the lesson as a whole and/or to specific words within each dialogue, so that, if the student doesn't know how to spell one of the words for not understanding its pronunciation, there will be a clue relating to that word. For example, if in the basic module of an English course the heard text was "this is a pencil" and the student could not make out the last word and wrote "this is a pen", the system will present the image of a pencil, at the same time as it pronounces the word "pencil".

The author agent is responsible for the creation of situations involving stories with images and recorded dialogues, which the student will use in the course. Using multimedia resources (microphone, video camera, videocassette, etc.), the author will develop an attractive course, making the learners and consequently the students feel motivated.

The student is represented in the system by the learner agent. So, each student that uses the system will have a learner agent to represent them. The learner assimilates the student's learning capacities, building a profile. Knowledge of the student's abilities will help the author suggest different forms to minister the subject's content in order to increase its efficiency and effectiveness. On the other hand, it can also serve the teacher, as a way of testing new methods or exercises. Each learner agent will know the learning profile of the student it represents. Through it, the student will enter classes that are available, with access to images and sounds, but not to text dialogues. In fact, the student's main activity is to reproduce the hidden text after listening once or twice to the sound of recorded dialogue, using the clues or not. The tool will make available a dialogue box with several indications to answer presented situations which will allow full interaction between the student and the system. The information in the dialogue's sequence will be transmitted through a window. In this phase, an algorithm will be used as comparison criteria which will count the amount of written words. If that number is different from the goal number, an important mistake has occurred. If, on the other hand, the number of words coincides and the spelling errors correspond to similar phonemes, such as $p h$ and $f$, only a "slight" mistake occurred. Otherwise, it will be important mistakes. The system will not present the correct answer while the student makes important mistakes. The options will be repeating the text, until hearing allows the identification of words and clues. This practice coincides with the one normally used by a human teacher on a classroom. When the student doesn't make any mistakes or only "slight" mistakes, then the system will consider the lesson's goals as achieved and will present the correct spelling of the words to the student.

In the case of distance education, consider, for illustration purposes, that in a Mathematics class, in which the approached subject is a first degree equation, for example, where the following equation is displayed to the student:

$$
3 x-4=2 x+5
$$


The student must solve the equation and after obtaining the answer, enter it on the indicated field in the text. Similar to the case of foreign language, the system will verify if student understands applying, in order, the three steps used for such, with the adaptation convenient to the characteristics of this discipline. It will also be used, in this case, as for any other discipline, as comparison criteria, an algorithm, not as a word counter, but as checker of solution, in the case of Mathematics, of local, in the case of Geography, of date, in the case of History, and so on.

The administrator agent manages the system and, therefore, must interact with all of the present agents. As an external observer of the author agent's activities and of the learner agent's evolution, the administrator can serve as a "critic" of the adopted didactic methodologies. This information, allied to the feedback given by the learners to the author, contributes to teaching methods and techniques more oriented to the goal of language teaching or other relevant disciplines. The knowledge associated to it is related to the systems administrative tasks such as configuration and performance statistics. It's through it and through their registration that the user has access to the tool. In this moment, besides welcoming, the administrator will ask the candidate some basic information, such as:

a. which foreign language course do you wish to attend or what language do you wish to learn? Or which discipline do you wish to attend?

b. what is you level of knowledge of the language (starter, medium, advanced, conversation, other)? Or of the discipline of interest. If the students answer "starter", it gives them an explanation of the course and how the system works; applies an exercise that allows access to material of classes in their level; and inserts them on the program. If the answer is not starter, they are invited to take a test to determine in which level they should start the intended course. Next, they get instructions about the course and how the system works; they are then invited to an exercise that allows access to class material, and then finally are informed that they are apt to use the system and are inserted in the program at the recommended level.

The agent will be available to the learner to help in the performance of lessons. Furthermore, it will identify the student's main difficulties by categorizing frequent doubts. This information can also contribute to the improvement of resource presentation under the author agent. On the other hand, the help agent itself can adapt, developing "tips" more oriented to the student's needs. The help agent will have knowledge associated to the more efficient form to help the system's agents, learners in particular.

The relationship of these four agent structures will allow knowledge exchange whenever one needs information from the other, will be object of definition during the software's elaboration and of the tool's implementation. When teaching a foreign language, each course (language) will be ministered in three modules: basic, intermediate and advanced, which will be detailed during the elaboration of the software and its respective implantation. Other disciplines will obey levels established by the official teaching system and respective Brazilian legislation, likewise, established during the confection of the software and implantation of the tool.

The tool will have a periodic evaluation system to test its efficiency, through user satisfaction, according to the users learning in the respective discipline. This evaluation, in the case of language teaching, will contemplate the pedagogical resources text, sound, image etc. and the use of the system. In any case, it will be based on indicators related to collaborative learning process, according to Collazos et al. (2007), properly adapted to such 
reality. For this effect, students will answer questions, which answers and suggestions, after being compiled, will serve as grounds to implement improvements in the system. This implies the use of a well defined and efficient communication protocol, with clarification of transmitted information resources, where ontologies, which have the role of facilitating the construction of a domain model in the Knowledge Engineering process, will be used. Besides, ontology will provide a vocabulary of terms and relations to which a domain can be modeled, therefore, will be used to guide the extraction and integration of relevant information from various structured sources. This will be used to fill the void between information conceptualization, both from the user's point of view, as from the ones offered by different information sources. This multimedia character of representation of information meets the need of application of different teaching methods that can vary according to the subject to the language of study or to the student's learning abilities.

The tool will be implemented by a team constituted of professionals of the information and communication technology area, professionals from the knowledge engineering and management area, informatics and language teachers, initially English and French, the first ones to be implemented. When it comes to implementing any other discipline as a distance education instrument, for example, besides these professionals, teachers of the respective disciplines to be included in the system will also participate. The participation of teachers of each discipline to be linked to the tool is indispensable to the efficiency and effectiveness in the teaching and learning process.

\section{Final considerations}

Immediately after the availability of the tool on the Web, there will be, with any language or discipline, a period of "validation" by the user of about six to twelve months, which will be monitored by the implementation team. During this period, in the moment of "registration", the student will be informed of this situation and invited to collaborate in the process. For that, as the tool is being used, a form will be filled, which will be available on the system, where the student is to write in any criticism, observations or suggestions to improve the system. This material is automatically sent to the team, which will analyze it and implement in the tool necessary adjustments, looking to optimize it.

The tool will offer the advantages of a foreign language teaching system, initially, English and French, permanently available on the Internet and of other general knowledge subjects. This will create the opportunity for a great number of people to study a foreign language or other disciplines, according to their conveniences, time and available hours, anywhere there is a computer connected to the Internet. This advantage, besides providing the opportunity of study to a great number of people, will favor a possible social policy of acquisition of community computers available for people of low income, especially, constituting a qualitative social cultural leap on the subject of general teaching and learning of a foreign language in particular, specifically in Brazil.

\section{Conclusions}

Multiagent systems offer consistent conditions to serve as base to construction and implementation of the proposed tool.

A tool to be implemented on a multiagents systems base will constitute a great advance on the teaching and learning of foreign languages or other disciplines binominal, in the 
Distance Education context, once communication and cooperation operated by agents are similar to the ones that occur between people in human society to perform certain activities. This authoring tool, continually available on the Internet, will present the flexibility that traditional courses usually don't have, particularly the foreign language ones. Besides the advantage of starting a course in whatever period, place and time, it will offer the possibility to restart it in any period in case an interruption occurs.

The tool will make possible the access to foreign language or other discipline courses, in the case of Distance Education, to anyone, at any time or place that has a computer connected to the Internet.

People who learn easily and have the time to progress faster on the learning of foreign languages or to improve their knowledge via Distance Education, will benefit, since they will learn the language or discipline of interest in shorter periods.

The tool to be implemented can be, in the future, a product used and disseminated by public schools, universities and companies.

The validation done by the system's users and the periodical evaluation to each it will be submitted will allow adjustments which will conceive its constant efficiency.

\section{References}

Ainsworth, S. (2007). Using a single authoring environment across the lifespan of learning, Educational Technology \& Society, Vol. 10 (N.3): 22-31.

Álvares, L. O. \& Sichman, J. (1997). Introdução aos Sistemas Multiagentes, Anais da $16^{\circ}$ Jornada de Atualização em Informática, Brasília-DF, pp. 1-38.

Araújo, M. M. S. de. (2007). O pensamento complexo: desafios emergentes para a educação on-line. Revista Brasileira de Educação, Vol. 12 (N. 36): 515-551.

Azevedo, W. (2000). Muito além do jardim da infância: o desafio do preparo de alunos e professores on-line. Conect@ $\mathrm{N}^{\circ}$ 2. Disponível em:

<http://www.revistaconecta.com/conectados/wilson_muito_alem.htm>. Acesso em: 30 jul. 2010.

Bailey, B. P. \& Konstan, J. A. (2000). Authoring interactive media. In: Webster, J. G. (Ed.), Encyclopedia of electrical and electronics engineering, John Wiley \& Sons, New York.

Barr, A.; Cohen, P. R. \& Feigenbaum, E. A. (1990). The handbook of artificial intelligence, Vol. 1, Addison-Wesley, Los Altos-California.

Beck, J.; Stern, M. \& Haugsjaa, E. P. (1996). Applications of AI in education. The ACM Digital Library, Vol. 3 ( $\left.\mathrm{N}^{\circ} .1\right)$ : 11-15. Disponível em:

<http://www.acm.org/crossroads/xrds3-1/aied.html>. Acesso em: 3 set. 2007.

Bittencourt, G. (2001). Inteligência Artificial Ferramentas e Teorias. Editora da UFSC, Florianópolis.

Brasil. (1996). Lei n. 9.394, de 20 de dezembro de 1996. Estabelece as Diretrizes e Bases da educação nacional. Legislação, Brasília, DF. Disponível em:

<http://www.planalto.gov.br/ccivil_03/LEIS/19394.htm>. Acesso em: 18 nov. 2003.

Bulterman, D. C. A. \& Hardman, L. (2005). Structured multimedia authoring, ACM Transactions on Multimedia Computing, Communications and Applications, Vol. 1 ( $\left.\mathrm{N}^{\circ} .1\right)$ : 89-109.

Clancey, W. J. \& Soloway, E. (1990). Artificial intelligence and learning environments, Artificial Intelligence, Vol. 1 ( $\left.{ }^{\circ} .42\right)$ : 1-6. 
Collazos, C. A. et al. (2007). Evaluating collaborative learning processes using system-based measurement, Educational Technology \& Society, Vol. 10 (N. 3): 257-274.

Courtillon, J. \& Raillard, S. A. (1983). Français langue étrangere: cours credif, Didier, Paris.

Coutaz, J. (1990). Interfaces homme-ordinateur: conception et réalisation, Bordas, Paris.

Crispim, H. A. F.; Abdalla JR, H. \& Molinaro, L. F. R. (2002). Proposta para um ambiente inteligente de ensino a distância, Anais do $9^{\circ}$ Congresso internacional de educação a distância, Associação Brasileira de Educação a Distância, Vila Mariana-São Paulo, pp. 36-53. Disponível em:

<http://www.abed.org.br/congresso2002/trabalhos/texto48.htm>. Acesso em 24 out. 2007.

Ferber, J. \& Gasser, L. (1991). Intelligence artificielle distribuée, Proceedings of 10th International Workshop on Expert Systems \& Their Applications, Cours No. 9, AvignonFrance, [s.n].

Fialho, F. A. P. \& Alves A. G. (2001). Agentes cognitivos na educação, Anais do $1^{\circ}$ Congresso Brasileiro de Computação, Vol. 1, Sociedade Brasileira de Computação, Itajaí-SC, pp. 173-183.

Gasser, L. (1992). Boundaries, identity and aggregation: plurality issues in multiagent systems, Werner.

Geymer, C. F. R. et al. (2003). SistEma Multiagente de Ensino e Aprendizagem na Internet (SEMEAI). Disponível em:

<http://www.inf.ufes.br/ sbie2001/figuras/artigos/a068/a068.htm>. Acesso em: 2 set. 2007.

Gilbert, D. A. \& Manny, A. (1996). Intelligent Agent Strategic. Disponível em: <http://activist.gpl.ibm.com:81/WhitePaper/ptc2.html>. Acesso em: 4 set. 2007.

Heilmann, K. et al. (1995). Intelligent agents: a technology and business application analysis. Disponível em: <http://haas.berkeley.edu/ heilmann/agents/index.tml>. Acesso em: 13 set. 2007.

Kaskalis, T. H.; Tzidamis, T. D. \& Margaritis, K. (2007). Multimedia authoring tools: the quest for an educational package, Educational Technology \& Society, Vol. 10 (N. 3): 135-162.

Lévy, P. Cibercultura. (2000). Editora 34, São Paulo.

Maia, C. \& Mattar, J. (2008). ABC da EaD - A educação a distância hoje, Pearson, São Paulo.

McArthur, D. J.; Lewis, M. \& Bishay, M. (2002). The roles of artificial intelligence in education: current progress and future prospects, Rand Corporation, Santa Monica.

Moran, J. M. (2003). Contribuições para uma pedagogia da educação on-line. In: Silva, M. (Org.). Educação on-line, Loyola, São Paulo.

Morin, E. (2004). Os sete saberes necessários à educação do futuro, Cortez, São Paulo.

O'connor, D. O. et al. (1996). Intelligent agents strategy: white paper, IBM Corporation, Research Triangle Park, North Caroline. Disponível em: <http:/ / activist.gpl.ibm.com/WhitePaper/ptc2.html>. Acesso em: 6 set. 2007.

Oliveira, F. M. de. (1998). Advances in artificial intelligence. In: Proceedings of $14^{\circ}$ Brazilian Symposium on Artificial Intelligence, Sociedade Brasileira de Inteligência Artificial, Porto Alegre. Porto Alegre, pp. 54-73.

Oliver, M. (2000). An introduction to the evaluation of learning technology. Educational Technology \& Society, Vol. 4 ( $\mathrm{N}^{\circ}$. 3): 20-30. 
Pettenati, M. C. et al. (2000). The learning tutor: a web based authoring system to support distance tutoring. Educational Technology \& Society, Vol. 3 (N. 4): 151-164.

Piaget, J. (1983). Psicologia da inteligência, Zahar, Rio de Janeiro.

Ramos, E. M. F. (1996). Educação e informática: reflexões básicas. Disponível em: <http://www.edit.inf.ufsc.br:1998/album99/referencias/Q1.htm>. Acesso em: 9 set. 2007.

Rossetti, A. G. et al. (2009). Ferramenta de autoria multimídia para ensino de língua estrangeira em ambiente multiagente. Educação e Pesquisa, São Paulo, vol. 35 (N.1): 81-97.

Rossetti, A. G. et al. (2006). Proposta de um ambiente multiagente para ensino de língua estrangeira multimídia, Anais da $3^{a}$ Conferência Sulamericana em Ciência e Tecnologia Aplicada ao Governo Eletrônico, Digital Ijuris, Curitiba, p. 47-54, DVD.

Russell, S. \& Norvig, P. (1995). Artificial Intelligence: a Modern Approach, Prentice Hall, Series in Artificial Intelligence, New Jersey.

Santos, C. T. dos \& Osório, F. S. (2003). Um ambiente virtual inteligente e adaptativo para a educação a distância, Anais do $14^{\circ}$ Simpósio Brasileiro de Informática na Educação, NCE - IM/UFRJ, Rio de Janeiro.

Silva, M. (2006). Educação online, Edições Loyola, São Paulo.

Urban-Lurain, M. (1998). Intelligent tutoring systems: an historic review in the context of the development of artificial intelligence and educational psychology. Disponível em: <http://www.cse.msu.edu/ urban/ITS.htm>. Acesso em: 13 set. 2007.

Virvou, M. \& Moundridou, M. (2000). A Web-based authoring too for algebra-related intelligent tutoring systems. Educational Technology \& Society, Vol. 3 (No. 2): 61-70.

Widdowson, H. G. (1991). O ensino de línguas para comunicação, Pontes, Campinas. 


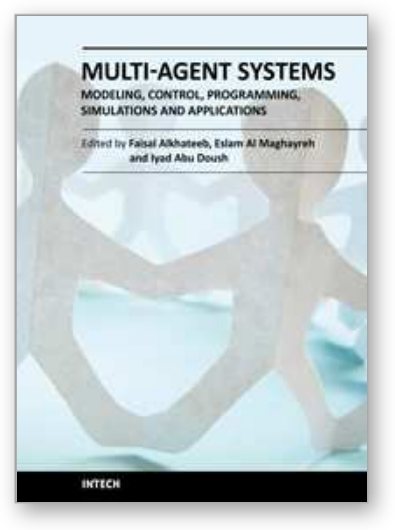

\author{
Multi-Agent Systems - Modeling, Control, Programming, \\ Simulations and Applications \\ Edited by Dr. Faisal Alkhateeb
}

ISBN 978-953-307-174-9

Hard cover, 522 pages

Publisher InTech

Published online 01, April, 2011

Published in print edition April, 2011

A multi-agent system (MAS) is a system composed of multiple interacting intelligent agents. Multi-agent systems can be used to solve problems which are difficult or impossible for an individual agent or monolithic system to solve. Agent systems are open and extensible systems that allow for the deployment of autonomous and proactive software components. Multi-agent systems have been brought up and used in several application domains.

\title{
How to reference
}

In order to correctly reference this scholarly work, feel free to copy and paste the following:

Adroaldo Guimarães Rossetti, Almir dos Santos Albuquerque, Vasco Pinto da Silva Filho and Rogério Cid Bastos (2011). Multimedia Authorship Tool for the Teaching of Foreign Languages and Distance Learning in a Multiagent Environment, Multi-Agent Systems - Modeling, Control, Programming, Simulations and Applications, Dr. Faisal Alkhateeb (Ed.), ISBN: 978-953-307-174-9, InTech, Available from:

http://www.intechopen.com/books/multi-agent-systems-modeling-control-programming-simulations-andapplications/multimedia-authorship-tool-for-the-teaching-of-foreign-languages-and-distance-learning-in-amultiage

\section{INTECH}

open science | open minds

\section{InTech Europe}

University Campus STeP Ri Slavka Krautzeka 83/A 51000 Rijeka, Croatia Phone: +385 (51) 770447 Fax: +385 (51) 686166 www.intechopen.com

\section{InTech China}

Unit 405, Office Block, Hotel Equatorial Shanghai No.65, Yan An Road (West), Shanghai, 200040, China 中国上海市延安西路65号上海国际贵都大饭店办公楼 405 单元 Phone: +86-21-62489820

Fax: $+86-21-62489821$ 
(C) 2011 The Author(s). Licensee IntechOpen. This chapter is distributed under the terms of the Creative Commons Attribution-NonCommercialShareAlike-3.0 License, which permits use, distribution and reproduction for non-commercial purposes, provided the original is properly cited and derivative works building on this content are distributed under the same license. 